\title{
Seating and Area Preferences in a College Reserve Room
}

\begin{abstract}
An investigation into the relationship between the architectural environment of a room and the patterns of seating preferences exhibited by library users. It was found that readers tended to locate themselves in order to avoid others. Also that the seat selected by the first person affected the choices of those who entered later.
\end{abstract}

"L

LIBRARY REPORTS are very rich in entrance and exit statistics, which show how many people come in and how many books are checked out, but there is a real gap in knowledge when it comes to what goes on during the reader's stay in the library."1 In view of this need, the following study attempts to analyze the relationship between seating preferences and architectural design.

Our psychological make-up contributes to the manner in which we perceive our physical and social environments. Space, an aspect of our surroundings, is an important determinant of how we react to one another, and to current situations. There are four kinds of space in human societies: home, public, interactional, and body (personal space). The primary emphasis of the present research

Diane Fishman and Ruth Walitt at the time this paper was written were students in the Graduate School of Library Science, Rutgers University, New Brunswick, New Jersey.

The authors wish to acknowledge the assistance of Dr. Ellis Ott, professor of Applied and Mathematical Statistics, and especially of their advisor, Dr. Henry Voos, associate professor, Graduate School of $\mathrm{Li}$ brary Science, for guidance in the preparation of this paper. is on the last type of territory.

Personal space may be defined as the distance that a living creature usually fixes between itself and others in its environment. Trespassers may not enter into this region which is always carried as a part of the organism wherever it goes. Through the process of socialization, this individual distance is developed.

It has often been observed in man and in other animals that there is a tendency to mark off definite zones which belong to them and cannot be invaded by others. This is known as territoriality. The main difference between this concept and personal space is that the former is relatively stationary. The tendency to mark off ones own territory has been noted in a variety of situations-bus terminals, geriatric wards, cafeterias, and as is especially relevant to this study, libraries. Physical objects such as coats, books, handbags, and personal belongings are often placed in front of empty chairs to delimit individual boundaries.

The library is an especially important institution in which personal space must be considered. Its patrons require a variety of physical comforts (ventilation, lighting, heating) as well as varying socio-psychological atmospheres. Depending upon the activities in which the users are engaged, they will demand different 
settings in which to study or socialize. When designing buildings of any type in the past, there has been a distinct lack of consideration by the architect for the sociological implications of structural planning for the occupants. Recently, there has been a greater coordination between behavioral scientists and architects in drawing up building blueprints. It is now recognized that the designer of a university library must take into account the following considerations: (1) the teaching and research needs of the university must be met by the library (2) there must be an awareness of all the programs which will take place in the library building, so that adequate space may be provided for them (3) the educational objectives of the university must be outlined, and (4) the building must be designed with all of the above in mind-i.e., form must follow function.

There is no one ideal building design that will satisfy the needs of all colleges and universities; however, when planning a structure, the users' needs are the crucial elements in the design process and should be given top priority. The architect must be aware of the importance of space, and its impact on our intellects and emotions. Yet the design of a building is complicated by the fact that "the effect of good design cannot always be anticipated because different people view the same environment in different ways, and in addition, the same people view the same environment differently over time." 2

"It is felt that there presently exists not only a lack of organization of empirical knowledge in the area of architecture and behavior but that there is also a pronounced lack of theoretical models for interdisciplinary research." ${ }^{3}$ However, there is general consensus among both architects and social scientists that future studies should be designed to investigate this area more fully.

\section{METHODOLOGY}

As part of our investigation of the relationship between human behavior and architectural design, we undertook to study the arrangement and selective occupancy by patrons in the reserve room in the main library of Rutgers University, New Brunswick, New Jersey. The purpose of the research was to determine if there were patterns of preference in relation to the area of the room and proximity to other people.

The reserve room is a large, open area ( 80 feet $x 100$ feet) below the main level of the library, which operates on a closed-reserve system (items must be checked out at a reserve desk). The room contains a total of thirty-five wooden, rectangular tables-twenty-three (four feet by nine feet) with six chairs, three per side; and twelve (four feet by six feet) with four chairs, two per side. Thus there is a total of 186 chairs around the tables. The latter are randomly arranged in various-sized rows utilizing the two types of tables. There is one row of carrels comprising twelve seats in the room. A total of twenty-eight desks are arranged in three rows with four others randomly placed in two corners of the room. Two of the perpendicular walls are picture windows. Thirty-three soft chairs (couches) are placed facing outwards along these walls. Thus the seating capacity in the reserve room is 262 people. (See Figure 1.)

In order to determine seating preferences of library patrons, we decided to conduct our observations when the reserve room first opened at 8:00 a.m. and continued them until approximately $9: 00$ a.m. The research was undertaken over two semesters-in the fall 1970, data were collected for fifteen weekdays, and in the spring 1971, for twenty weekdays. In addition, other areas of the library were also analyzed. As each person selected a seat, the order of occupancy, the furniture location, and use or non- 


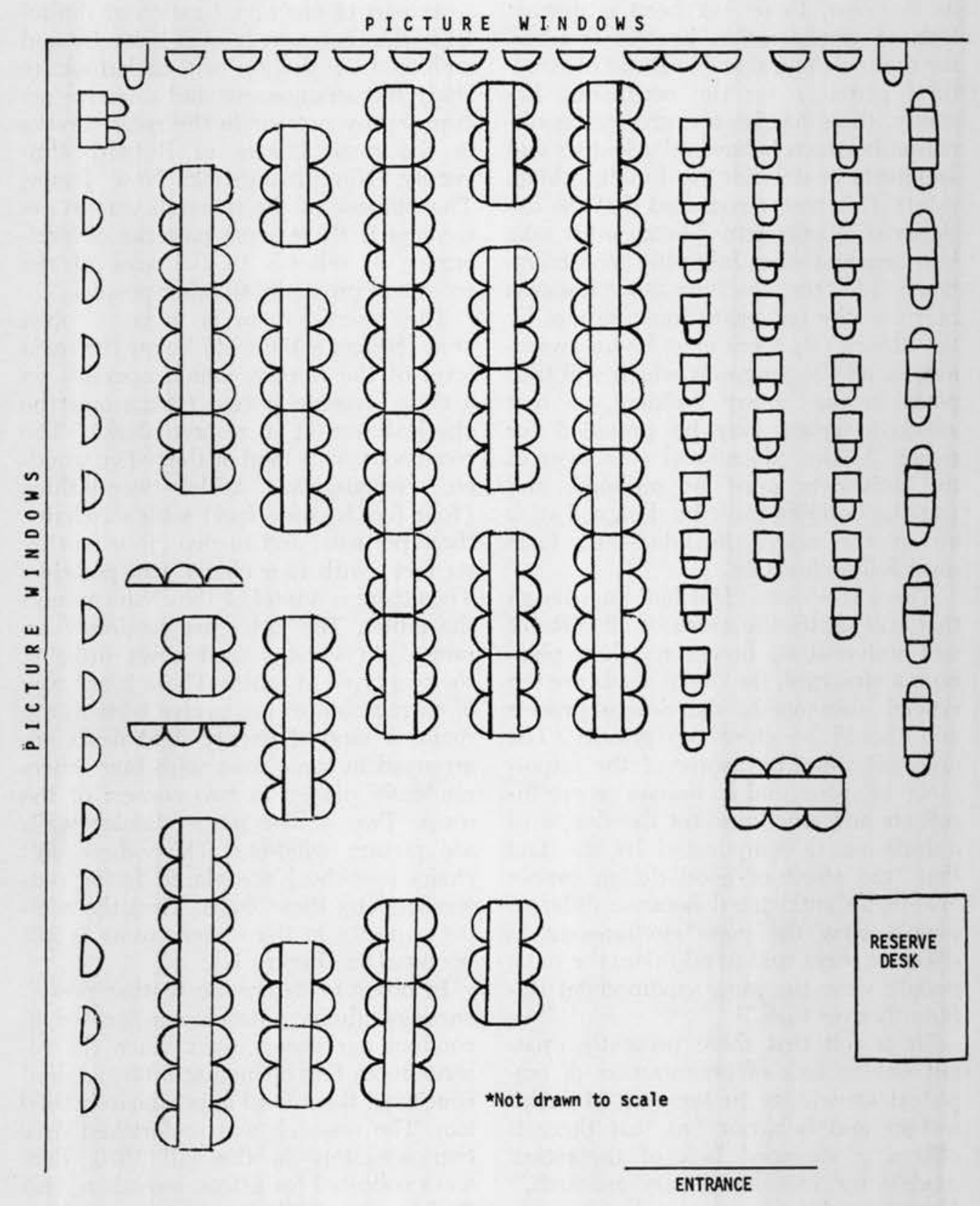

Figure 1 
use of reserve material (spring term only) were noted. As the early morning use of the reserve room varied considerably from day to day during the two semesters, only the first ten people (fall term) and the first twelve people (spring term) were included in our data to create uniformity. These particular numbers (ten and twelve) were chosen because on certain days these were the maximum numbers of people who entered during the limited time we had available before classes.

\section{Results}

One of our primary objectives was to determine at what position people prefer to sit at a six-man table.

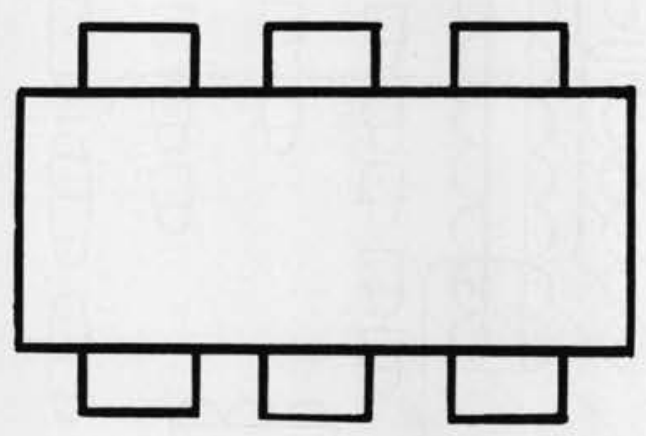

Figure 2

Diagram of Six-Man Table

We analyzed the data in terms of the end seats versus the middle seats. The percentages for both semesters in the reserve room were similar: fall term81.8 percent (ends), 18.2 percent (middle); spring term-82.6 percent (ends), 17.4 percent (middle). The other areas observed (periodical reading area and general reading area), although based on a small sample size, also substantiated these findings.

In order to discover if there was a preference for the front of the reserve room (that half closest to the entrance and the reserve desk) as opposed to the back, we divided the floor plan approximately in half. This division was analyzed in two ways, horizontally and diagonally, in order to determine if there was a difference between the two. (See Figure 3.)

In regard to this sectioning, we assessed the seating preferences of users and non-users of reserve material. Contrary to our expectations, there were not significantly more reserve users in the front as opposed to the back of the room, regardless of the type of division used. (See Table 1.)

We used these two methods of sectioning (and added an additional diagonal in the opposite direction) and calculated the total occupancy of the front versus the back of the room. (See Figure 3 for methods of division.) In the fall semester, the percentages were almost identical for the two methods of division: front-sixty-eight percent (solid diagonal) versus 67.3 percent (horizontal). There was slightly more variation when using the dotted diagonal: front -57.3 percent. The spring semester showed slightly greater diversity between the solid diagonal and horizontal: front-58.8 percent (solid diagonal) versus 54.2 percent (horizontal). When also considering the dotted diagonal (front-49.6 percent), there was more similarity in the percentages as compared to the fall. (See Table 2.)

It would be expected that a greater proportion of the reserve room would be occupied by people using reserve material. However, as our results show, we did not find such a difference in the early morning-using reserve materials: 126 (52.5 percent); using non-reserve materials: 114 ( 47.5 percent).

One of the main aspects in our study of seating preferences was the effect of the presence of seated patrons on incoming patrons. This was analyzed with respect to the tendency to sit in the front or the back of the room. We acquired data for both the fall and spring terms on the percentages of the first people who sat in the front or back of the room 
PICTURE WINDOWS

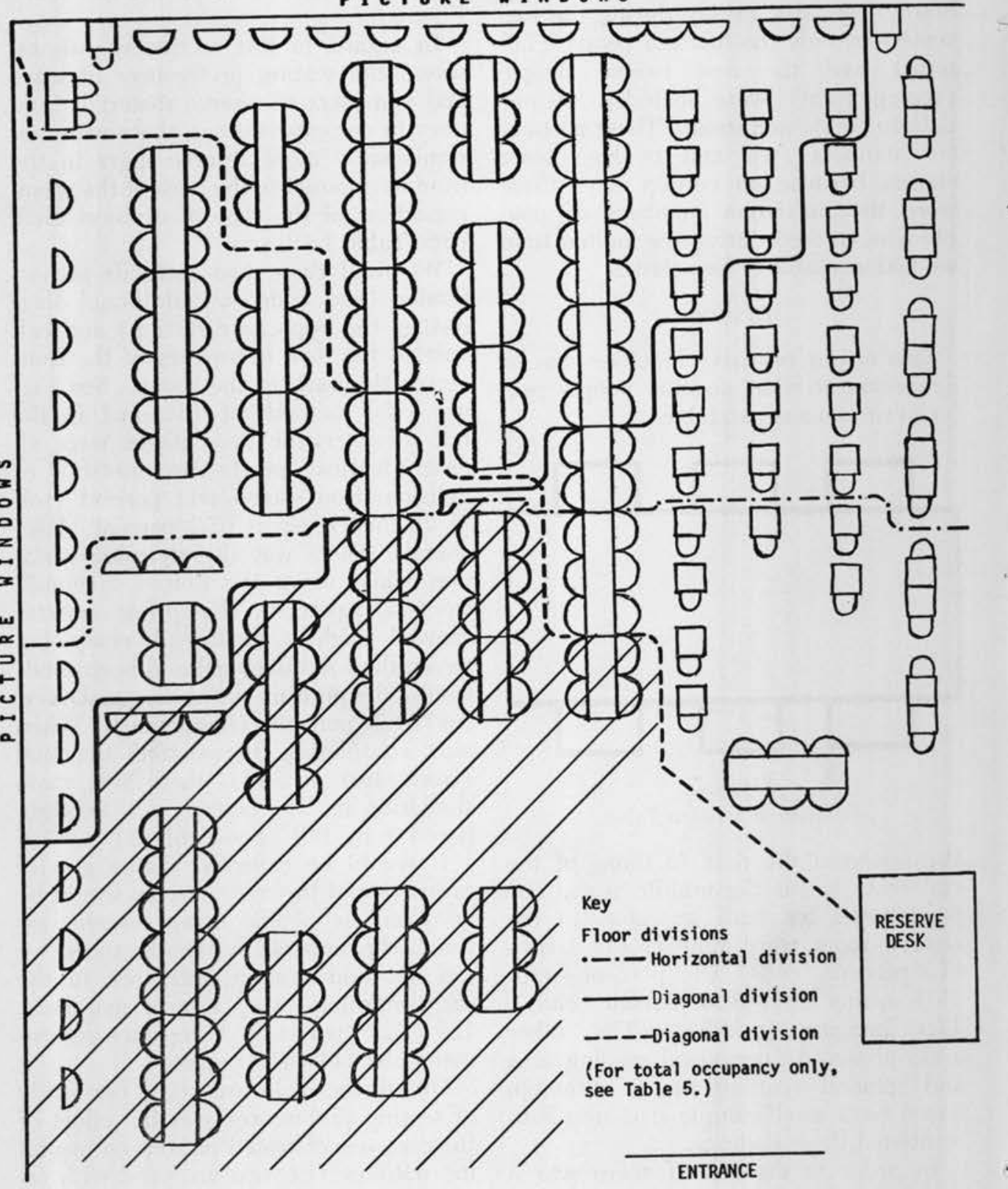

Figure 3

Division of the Floor Plan 
TABLE 1

Actual Numbers and Percentages of Users of Reserve aNd Non-Reserve Materials

\begin{tabular}{lcccc}
\hline \hline & \multicolumn{2}{c}{ Horizontal Division } & \multicolumn{2}{c}{$\begin{array}{c}\text { Diagonal Division } \\
\text { Front }\end{array}$} \\
\hline Back & & \multicolumn{2}{c}{ Back } \\
\hline Reserve & $75(57.7 \%)$ & $51(46.4 \%)$ & $80(56.7 \%)$ & $46(46.5 \%)$ \\
Non-Reserve & $55(42.3 \%)$ & $59(53.6 \%)$ & $61(43.4 \%)$ & $53(53.5 \%)$ \\
Total & 130 & 110 & 141 & 99 \\
\hline
\end{tabular}

TABLE 2

Percentages and Actual Numbers of Total RoOM Occupancy by Method of Division, AREA OF RoOM, AND SEMESTER

\begin{tabular}{lll}
\hline \hline & \multicolumn{1}{c}{$\begin{array}{c}\text { Front Section of Reserve Room } \\
\text { Fall }^{\circ}\end{array}$} \\
\hline $\begin{array}{c}\text { Horizontal } \\
\text { Division }\end{array}$ & $67.3 \%(101)$ & $54.2 \%(130)$ \\
$\begin{array}{c}\text { Solid Diagonal } \\
\text { Division }\end{array}$ & $68 \%(102)$ & $58.8 \%(141)$ \\
$\begin{array}{c}\text { Dotted Diagonal } \\
\text { Division }\end{array}$ & $57.3 \%(86)$ & $49.6 \%(119)$ \\
\hline
\end{tabular}

- Fall percentages based on sample size of 150 .

† Spring percentages based on sample size of $\mathbf{2 4 0}$.

during each observation. This process was continued for each person who entered. We divided the room by the two types of division-horizontal and diagonal. There was a similarity among the percentages of people in the front using the horizontal division versus the front with the diagonal division for each of the order preferences. These results were generally not as close as those found for the total number of people in the front, contrasting the two types of divisions. Although the actual percentages of front versus back occupancy differ for the two semesters, there is a tendency for the percentage of people choosing the front section to be initially high and then decrease as more people enter the room (although this is more obvious in the spring data). (See Table 3 for complete figures.)

In order to discover if this was a significant finding, we graphed the cumulative averages of the percentages of people choosing the front for each person in the order they entered the room (i.e., the percentage of the first people who entered the room and sat in the front during the observed interval was calculated; percentage of second people, etc.; these percentages were then cumulated and averaged). (See Table 4.)

It is obvious from Figure 1 that there is a decrease in the preference for the front with increasing numbers of people. If an infinite number of people were to be observed, a certain point would be reached where patrons would be "forced" to sit in the back due to a lack of empty seats in the front. However, in the fall semester, after the sixth person had entered, there is a greater decrease (.722 to .686$)$ in the tendency to sit in the front. In the spring, this marked decline (.589 to .556 ) occurs after the ninth person had entered. Because there are so few people sitting in the front in each instance when this point is reached, the patrons are still able to make a free choice as to where to sit. This choice is to occupy the back. Although both graphs decrease, they are not identical-the slope for the fall semester is more gradual. However, if the data for the first occupants are excluded, the slopes become more similar. At the point where the graph falls below fifty percent, more people will be choosing to sit in the back. This number of persons will vary depending upon the semester considered and whether the first occupants are included. If the complete data is examined, the shift towards the back occurs after 77.4 people for the fall and 28.8 people for the spring. By excluding the first occupants, this deciding number gets closer-after 66.1 people for the fall, and after 32.2 


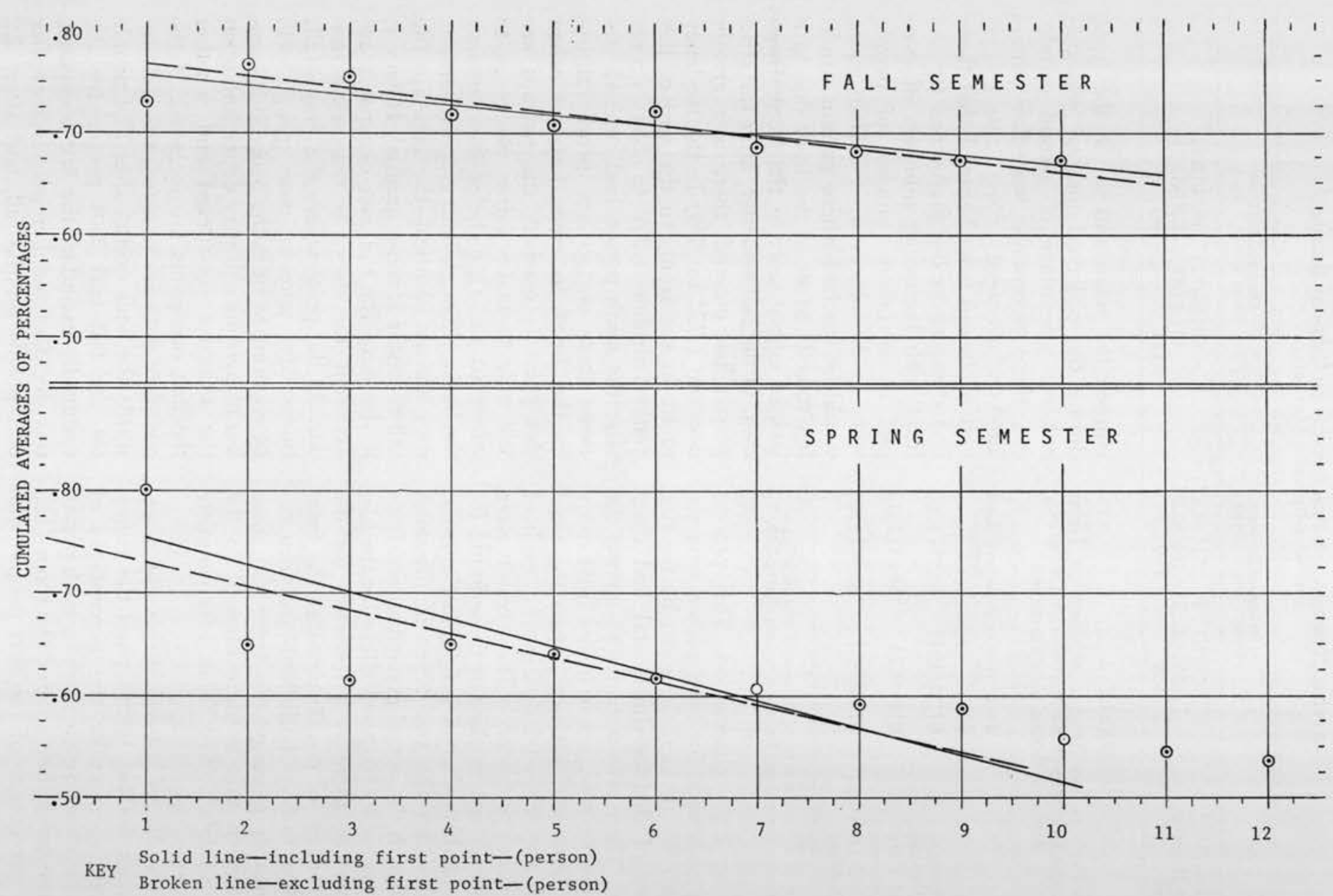

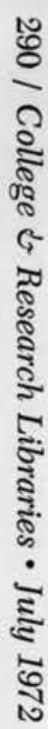

Figure 4 
TABLE 3

Percentages of Order Preferences by Area of Room, Method of Room Division, and SEMESTER

Front Section of Reserve Room

\begin{tabular}{ccccc}
\hline \hline Order Preference & \multicolumn{2}{c}{$\begin{array}{c}\text { Fall Semester } \\
\text { Diagonal Division } \\
(\%)\end{array}$} & $\begin{array}{c}\text { Spring Semester } \\
\text { Horizontal Divisional Division } \\
(\%)\end{array}$ & $\begin{array}{c}\text { Diagonal Divion } \\
(\%)\end{array}$ \\
\hline 1 & $73.3 \%$ & $80 \%$ & $80 \%$ & $85 \%$ \\
2 & 80 & 80 & 50 & 60 \\
3 & 73.3 & 73.3 & 55 & 60 \\
4 & 60 & 46.7 & 75 & 65 \\
5 & 66.7 & 80 & 60 & 60 \\
6 & 80 & 60 & 50 & 55 \\
7 & 46.7 & 60 & 55 & 50 \\
8 & 66.7 & 73.3 & 50 & 50 \\
9 & 60 & 66.7 & 55 & 50 \\
10 & 66.7 & 60 & 25 & 45 \\
11 & & & 45 & 70 \\
12 & & & 45 & \\
\hline
\end{tabular}

- Fall percentages based on 15 observations.

- Spring percentages based on 20 observations.

TABLE 4

Cumulated Averages of Percentages

\begin{tabular}{ccc}
\hline \hline $\begin{array}{c}\text { Order } \\
\text { Preferences }\end{array}$ & $\begin{array}{c}\text { Fall } \\
\text { Semester }\end{array}$ & $\begin{array}{c}\text { Spring } \\
\text { Semester }\end{array}$ \\
\hline 1 & .733 & .800 \\
2 & .767 & .650 \\
3 & .755 & .617 \\
4 & .717 & .650 \\
5 & .707 & .640 \\
6 & .722 & .617 \\
7 & .686 & .607 \\
8 & .683 & .594 \\
9 & .674 & .589 \\
10 & .673 & .556 \\
11 & & .545 \\
12 & & .538 \\
\hline
\end{tabular}

people for the spring. To determine if there was a significant relationship between this data for the two terms, we calculated the Pearson product moment coefficient of correlation-for all the data, it was .462. By excluding the first occupant, it increased to .642 .

In relation to the total occupancy of the room, we observed (during each semester) that there were islands of nonuse-i.e., the seats at some of the tables were never occupied (during any one semester). This finding was established by analyzing the floor plan according to frequency of use. (See Figures 5 and 6.)
We calculated the correlation coefficient for the total room, for the two sets of data, in order to determine if a relationship existed. This was accomplished by comparing the occupancy of all the rows of contiguous tables, for the two terms. The obtained coefficient-.686, is quite high and shows that there is a relationship between the total occupancy of the room by area. As there were noticeable differences in frequency of use of the table seats for both semesters, we calculated the correlation between the data for selected areas of the room. In comparing the row of tables closest to the windows (Section I, Figure 5), the correlation coefficient was found to be .79 (indicating a significant relationship). The second area that was compared was the rows of tables in the foremost part of the room (Section II, Figure 5). Here the relationship again (.68) was quite high. A third group of tables, toward the middle of the room (Section III, Figure 5) yielded a correlation of .78 .

We attempted to measure preference for particular type of furniture by its availability. However, we were not able to arrive at any significant conclusions due to insufficient data. 
292 / College d Research Libraries • July 1972

P I CTURE WINDOWS

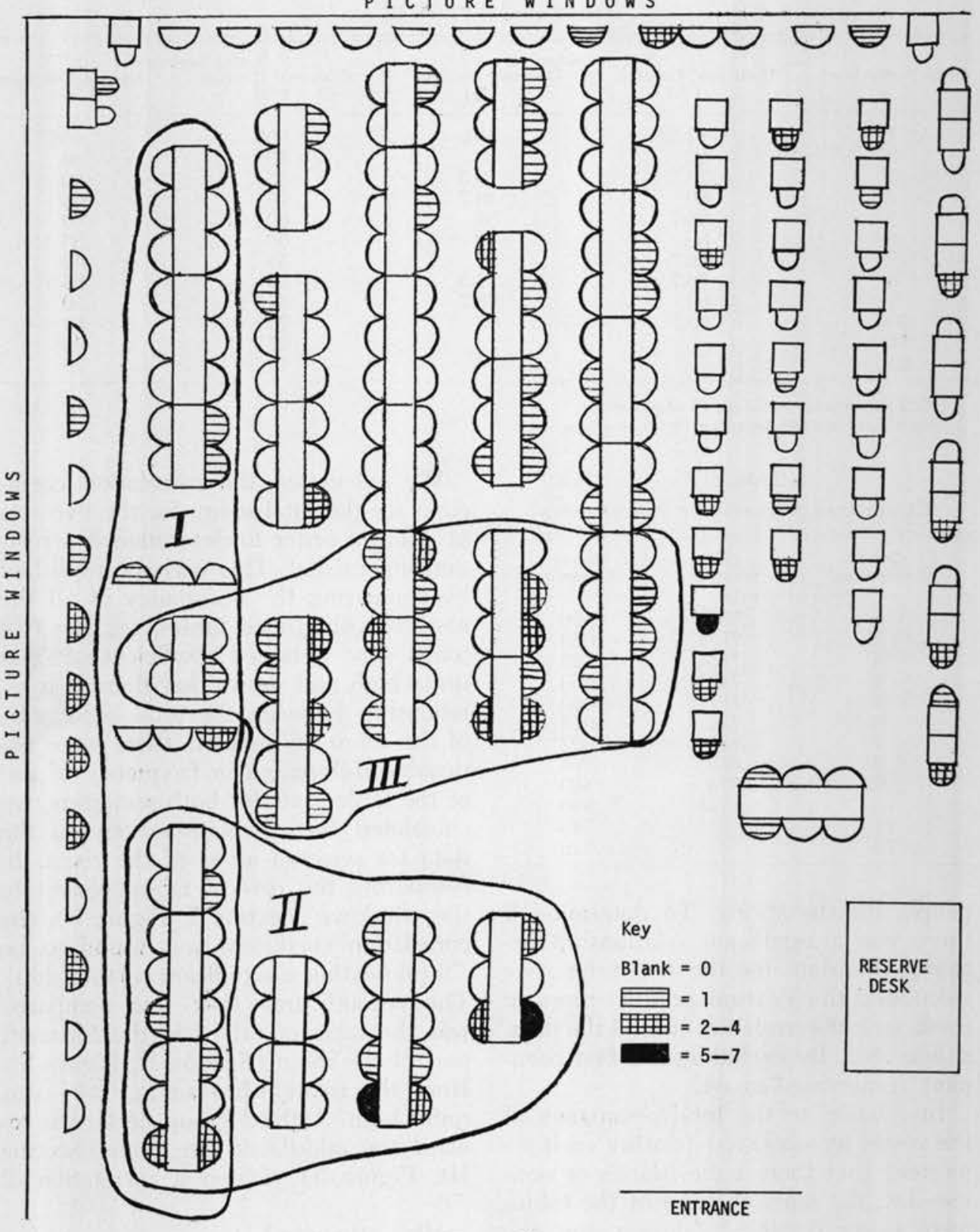

Figure 5 
PICTURE WINDOUS

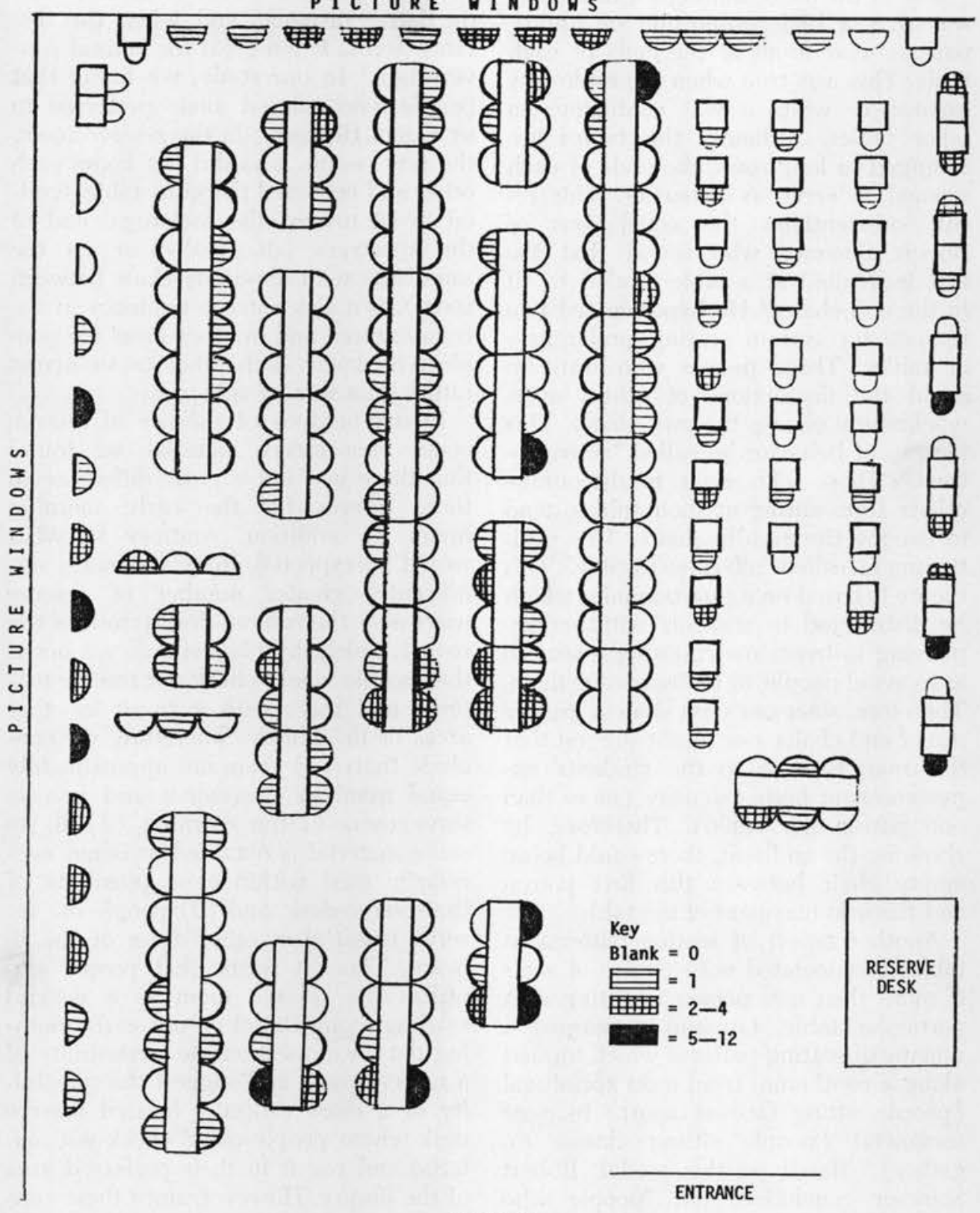

Figure 6 


\section{Discussion}

One of the major findings of this study was that a high proportion of library patrons tend to sit at the ends of each table. This was true when the table was isolated or when it was contiguous to other tables. Although the tables are arranged in long rows, the ends of each seemed to serve as a barrier. This result substantiates the conclusions of Robert Sommer who found that the first individual at a table tended to sit in the end chairs. ${ }^{4} \mathrm{He}$ hypothesized two reasons for certain seating preferences at tables. Those people who want to avoid the distractions of others overwhelmingly choose the end chairs. This pattern of behavior he called "active retreat." Those who want to discourage others from sitting at their tables, tend to occupy the middle chairs. This positioning he called "offensive display." This theory is based on a questionnaire which he distributed to students with accompanying instructions-choosing a seat so as to avoid people, or to discourage them. Therefore, since our data show a greater use of end chairs, one might suggest that this may be due to the students' expectations of higher density (more than one patron per table). Therefore, by choosing the end seat, there could be an empty chair between this first patron and the next occupant of the table.

Another aspect of seating patterns at tables is associated with choice of seats if more than one person is sitting at a particular table. Osmond developed a scheme of seating patterns which formed along a continuum from most sociofugal (people sitting farthest apart) to most sociopetal (people sitting closest together). ${ }^{5}$ Based on this model, Robert Sommer concluded that "people who came alone did indeed prefer to sit alone. When room density reached one per table, then the next preferred arrangement was diagonal seating." ${ }^{\prime}$ Sommer also found that people prefer to sit across from each other rather than side by side except when the distance between opposite chairs is greater than the latter distance, and when the distance across is too great for normal conversation. ${ }^{7}$ In our study, we found that people who entered alone preferred to sit alone. However, in the reserve room, the few people who did not know each other and occupied the same table, tended to sit toward the sociofugal end of the spectrum (diagonally, or on the same side with an empty chair between them). We also noted a tendency in the reserve room and in other areas for people who knew each other to sit across rather than side by side.

In our analysis of the use of reserve versus non-reserve material, we found that there was not a great difference in these figures for the early morning hours. In addition, contrary to what would be expected, there was not a significantly greater number of reserve users near the reserve desk (front of the room). Solely by observation, we noted that people would check out reserve material and leave with it to sit in other areas of the library. Therefore, we conclude that: (1) there are approximately equal numbers of reserve and non-reserve users in the morning (2) if reserve material is obtained, it is not necessarily used within close proximity of the reserve desk, and (3) people use reserve material in other areas of the library. Thus, it seems that people also utilize the reserve room as a general reading room. Based on our early morning data, we question the advisability of a reserve room and suggest the possibility of a more centrally located reserve desk where people could check out material and use it in their preferred area of the library. However, since these conclusions are based on a limited time sample, further studies would have to be conducted to determine if these conditions existed throughout the day.

We conclude from our observations 
that the presence of a very small number of people does have a large effect on incoming patrons. Their behavior seems to suggest a desire to avoid others. All of our data show that even though there may be only a few people sitting in the front, there is an increasing tendency for the next to choose the back. Our statistics seem to indicate that the first person has a considerable effect on the future seating pattern of the entire room. By including the first occupant, the two graphs are quite different. However, if the first occupant is excluded from consideration, the graphs become more similar, and thus the areal seating preferences become more alike. In substantiation of this closer relationship, by excluding the first occupant, the correlation between the cumulated averages of the percentages of people sitting in the front for the fall and spring data also increased.

In analyzing the occupancy of front versus back in reference to order preferences and use of reserve materials, we had sectioned the room diagonally and horizontally. In addition, we also examined the total occupancy in three methods-horizontal and opposite diagonals. Although the use of two divisions showed a close relationship, the addition of the second diagonal created a triangle of overlap and thus narrowed the area examined. Since a similar percentage of people were seated in this region (see Figure 3), whatever method of sectioning is used, this area would prove to be a significant factor in the seating pattern of the reserve room.

We were also able to confirm, solely through observation, the tendency for people to mark off their own territory. This behavior has been noted among persons waiting in stations, cafeterias, etc. In fact, these actions have been carried to the extent that people often indicate "favorite" seats and are greatly disturbed if others are occupying these positions. In the library, patrons were often seen to place books, coats, briefcases, and umbrellas on seats next to them thereby discouraging others from sitting nearby and also delineating their space. When away from their seats, they often put some article of property in front of the place they were occupying. In regarding favorite seating areas, we did not test this hypothesis through questionnaires or keeping records. Yet, after sitting in the reserve room for several days, we did note the tendency for certain individuals to occupy the same seat numerous times. However, on an occasion, one patron refused to sit in his usual seat, because of its close proximity to another individual. These findings are further examples of individuals' tendencies to sit in avoidance of other patrons, or in other words, to sit defensively.

In the results noted above pertaining to total occupancy of the reserve room, it was stated that there were broad areas of non-use of the tables for both semesters. In addition other regions were used in varying degrees, ranging from a low of one time during our observational period to a high of twelve times. Through inspection, it was impossible to find a significant relationship between these two sets of data, but the correlation for the entire room was quite high. The randomly selected areas also yielded significant correlations. Therefore, on the basis of these results, one can conclude that seating patterns are established in the room. However, since our study was conducted in the early morning, when there was very low room density, it is difficult for us to determine why such area preferences exist, including distinct regions of non-use. Further study of this seating behavior is indicated.

In one of his studies, Robert Sommer concluded, on the basis of a questionnaire, that there were differences between carrel users and other students. ${ }^{8}$ The former seemed to be more motivated than other patrons to isolate themselves. In the reserve room currently be- 
ing analyzed, carrels accounted for only twelve of the 263 seats in the total room. However, on the basis of observations, carrels seem to be used more frequently. This is a further substantiation of patrons' desires to actively avoid others or to seek privacy.

Although avoidance behavior was frequently noted, all four types of furniture were used indicating that a diversity of needs persists. The design of library facilities requires that the architect take into consideration the personalities of the patrons and the activities of the library. An optimal situation would be the provision of a variety of areas-private study rooms, large reading areas, discussion areas, etc. An economical way to meet these structural requirements would be to build flexibility into the library, so that the same room can be used for various purposes.

\section{Conclusions}

1. The vast majority of users preferred to sit at the ends of six-man tables rather than the middle, and each contiguous table seems to be treated as a separate entity.

2. There was not a significant difference between the total number of reserve and non-reserve users.

3. There is a consistent percentage of people occupying the front central area of the reserve room.

4. The first occupant of the reserve room has an influence on the subsequent seating pattern.

5. Occupancy of the front of the reserve room is initially high and tends to decrease as more people enter. This shift will occur with only a small number of people in the room.
6. There is a distinct preference to occupy specific regions of the reserve room, and, therefore, some areas were never used.

7. All the data supports the conclusion that there is active avoidance or a tendency to seek privacy on the part of the library's patrons.

\section{ReCOMMENDATIONS}

Through our survey of the literature, we have found that very few sources deal with the problem of architectural design and behavior. There is a noticeable lack of empirical knowledge concerning people's preferences and environmental needs. Therefore, we recommend that additional studies be undertaken to fill this void. In this way, structural planning may more closely coincide with the socio-psychological requirements of users.

More specifically, we recommend an in-depth investigation of why there are choices for particular areas of a room. Knowledge of the reasons for regional preferences may well have large implications on future library design. The use of questionnaires to discover the subjective needs of patrons is advocated. Observational data alone may distort the true situation and, therefore, two-way communication between planners and users is desirable. Because our data were limited in the time sample investigated, similar analyses should be extended throughout the day to discover if our results can be generalized. In relation to the Rutgers University reserve room extended time studies are advisable, particularly in regard to use of reserve material, to substantiate our view that the present reserve system is unwarranted.

\section{REFERENCES}

1. Sommer, Robert. "The Ecology of Privacy," Library Quarterly 36:234-48, July 1966, p. 235.
2. Lynch, Kevin, et al. Open Space for Human Needs. Washington, D.C.: Marcon O'Leary \& Assocs., 1970, p. 45. 
3. Good, Lawrence R. "Architectural Environment and Human Behavior," Kansas Journal of Sociology 1, 2:56-60, 1965, p. 56 .

4. Sommer, Robert. "The Ecology of Privacy," p. $244-45$.

5. Osmond, Humphrey. "The Relationship Between Architect and Psychiatrist," Psychiatric Architecture, C. Goshen (ed.), Washington, D.C., American Psychiatric Associa- tion, 1959.

6. Sommer, Robert. "The Ecology of Privacy," p. 236.

7. Sommer, Robert. "Leadership and Group Geography.” Sociometry 24:99-110. March 1961 , p. 106.

8. Sommer, Robert. "Reading Areas in College Libraries," Library Quarterly 38:249-60, July 1968 , p. 257. 